\title{
Do fenômeno da globalização e seus reflexos no Direito Internacional contemporâneo
}

\author{
The globalization and its reflects in contemporany International Law
}

Leonardo Melo Matos ${ }^{1}$

\begin{abstract}
Resumo
$\mathrm{Na}$ atualidade o mundo tem assistido às revoluções que vêm ocorrendo no Oriente, onde a principal reivindicação é a alternância de poder e maior abertura democrática. Tais revoluções são frutos de um fenômeno a que vem passando 0 mundo, sobretudo desde o século XX pós-guerra, na cada vez maior integração dos países representada pelo processo da globalização. Tal processo, quiçá irreversível, apresenta grandes reflexos sobre o Direito Internacional, que tem a necessidade de compreender as suas raízes históricas e se prestar a acompanhar este fenômeno, que representará cada vez mais na importância do Direito Internacional.
\end{abstract}

Palavras Chave: Soberania; Globalização; Desenvolvimento; Direito Internacional.

\section{Abstract}

The world watches the revolutions that are happening at East, where the main demand is the alternation of power and democratic openness. Such revolutions are the result of a phenomenon that has experienced the world especially from the XX century postwar period, the increasing integration of the countries represented by the process of globalization. Such a process, maybe irreversible, has major repercussions for International Law, which has a need to understand their historical roots and is provided to monitor this phenomenon, which represent increasingly important in International Law.

Keywords: Sovereignty; Globalization; Development; International Law.

\section{Introdução}

0 presente estudo busca tecer um breve ensaio sobre a questão pontual da globalização relacionada com três aspectos principais: a soberania, sobretudo em sua concepção na atualidade, o desenvolvimento (sob o enfoque do aspecto econômico, social e

\footnotetext{
${ }^{1}$ Graduado em Direito pela Universidade Estadual de Londrina; discente do curso de Especialização em Direito Empresarial com Ênfase em Direito Tributário pela Universidade Norte do Paraná; Advogado atuante nas áreas de Direito Civil, Empresarial, Tributário e Eletrônico. Contato: leonardommatos@gmail.com
} 
humano) e por fim a implicância de tal fenômeno sobre o Direito Internacional contemporâneo.

O fenômeno da globalização é inevitável e vem sendo posto à prova sobretudo com as eclosões das que estão sendo denominadas "revoluções democráticas" que ocorrem na atualidade no Oriente, sobretudo no Oriente islâmico. Verifica-se um anseio por parte da própria população de buscar uma maior abertura e proximidade com o Ocidente.

Em um primeiro momento, discorrer-se-á sucintamente a doutrina tradicional do Direito Internacional e a clássica divisão da teoria monista e dualista, a fim de que se forme a base necessária para compreender os desafios que o Direito Internacional deve enfrentar com o avanço do fenômeno da globalização.

Num segundo momento analisar-se-á o conceito de soberania, fazendo um giro histórico até chegar-se ao conceito de soberania no século XXI. Depois discorrer-se-á propriamente sobre o fenômeno da Globalização, fazendo paralelo com a noção de Desenvolvimento e uma breve consideração sobre os papéis das organizações internacionais.

Feitas essas considerações, far-se-á a inter-relação existente entre os diversos conceitos e a sua relação com o Direito Internacional contemporâneo, com os desafios que devem ser enfrentados e a realidade que necessita ser assimilada.

\section{Das teorias do Direito Internacional}

É clássica a divisão do Direito Internacional e a sua relação com o ordenamento jurídico pátrio através de duas teorias, quais sejam, a monista e dualista, divisão essa que teria vindo de estudos realizados já no século XIX. Tal classificação mostra-se ainda útil para ajudar a entender de que forma o Direito de cada nação se porta frente às normas internacionais.

O Direito Internacional foi tomando forma e consistência ao longo dos séculos e atualmente apresenta um caráter corporativo, mormente em se tratando da atuação dos Organismos Internacionais. Costuma-se apresentar que o Direito Internacional possui dois elementos: um de coesão e outro de tensão.

O elemento de coesão visa a harmonizar e a compatibilizar a relação existente entre o Direito interno e externo, e sobretudo compatibilizar as relações que existam entre os 
Estados ou partes de diferentes estados, a fim de que haja um mínimo de segurança jurídica, estabelecendo critérios válidos para a resolução de conflitos e um mínimo de normatividade aplicável a dois ordenamentos distintos.

Por outro lado, inevitavelmente tem-se 0 elemento de tensão, que se revela quando há possível atrito entre norma de caráter interno e nacional e norma externa a qual - Estado tenha aderido, gerando um conflito entre essas normas. E precisamente o modo pelo qual tais normas são integradas e compatibilizadas ou qual prepondera no caso concreto, que se leva em consideração o sistema monista ou dualista.

A grande dificuldade para a solução deste problema que tende a crescer cada vez mais, visto que se tem observado com maior freqüência uma internacionalização do Direito, reside justamente na falta de uniformidade de adoção de critérios entre os países, e, sobretudo, por se tratarem os ordenamentos jurídicos internos e internacionais de diferentes fontes jurídicas originárias.

0 primeiro estudo sistemático nesse sentido foi feito por Heinrich Triepel em 1899, na obra Volkerrecht und Landesrecht, que foi desenvolvida por Dionisio Anzilotti, ambos pertencentes à teria dualista (M ELLO, 2004, p. 121, V.1)

Para o dualismo as ordens jurídicas internas e internacionais "podem ser tangentes, mas não secantes, isto é, são independentes, não possuindo qualquer área em comum" (MELLO, 2004, p. 121). Para os dualistas o Estado é sujeito de Direito Internacional e os indivíduos sujeitos de direito interno.

0 monismo, por sua vez, não aceita a existência de duas ordens jurídicas autônomas convivendo em harmonia. Para tal teoria, existe a preponderância de uma ordem jurídica, seja ela qual for. E qual deve prevalecer em caso de um eventual conflito?

Por um lado existe a escola da primazia do Direito Internacional sobre o interno, 0 que já fora esboçado pela Escola de Viena (cujos principais expoentes são Kelsen, Verdross e Krunz), com destaque de Kelsen, através de sua teoria do direito puro e a lógica da pirâmide. Kelsen entende que as normas superiores prevalecem sobre as inferiores e a norma de Direito Internacional estaria acima das normas internas.

Por outro lado, há a escola da primazia do Direito interno, nacional, tendo suas raízes no hegelianismo, o qual considera o Estado detentor de uma soberania absoluta e o direito internacional visto como um direito interno, mas aplicado para assuntos externos, 
envolvendo outros estados, sendo os precursores dessa corrente Werzel, os irmãos Zorn, Decencière-Ferrandière, Korovin, George Burdeau e Verdross.

Há que se ressaltar que há ainda as chamadas teorias conciliadoras, a exemplo da doutrina espanhola, que vêem como independentes as ordens jurídicas internas e internacionais, mas unidas por um elemento de coordenação (M ELLO, 2004, p. 125). Tais teorias buscam, em síntese, conciliar as falhas ou limitações das teorias clássicas.

\section{0 conceito de soberania no século XXI}

Um tema pertinente e que possui ampla relação com a questão da aplicação do Direito Internacional, diz respeito ao conceito de soberania e o seu entendimento na contemporaneidade. Isso porque se costuma dizer que a soberania é a base do Direito Internacional.

Para entender de forma plena o conceito, faz-se necessário uma breve retomada histórica do desenrolar do tema em cada época, através da evolução dos estudos, culminando, porquanto, no conceito moderno de soberania.

0 primeiro ponto a se destacar se refere à perspectiva dada pelos gregos ao assunto, pois os mesmos tinham em mente a idéia de auto-suficiência, com a polis sendo a grande provedora das necessidades inerentes a um processo de socialização avançado (NUNES JUNIOR, 2003, p. 145-146).

Vale lembrar que as estruturas integrantes dessa sociedade não eram complexas, não havendo que se lidar com fenômenos de poder muito desenvolvidos.

Um segundo paradigma é a Idade Média, época marcada pela tripartição do poder entre a Igreja Católica, juntamente com o Império Romano e as grandes corporações, sendo que não há como falar-se em soberania em uma sociedade marcada pela fragmentação e preponderância de instituições descomprometidas com um processo de centralização.

O medievo, aliás, é marcado justamente por uma ausência de noção de soberania enquanto atrelado à idéia de nação. Pode-se dizer que na Idade M édia houve uma completa descentralização, sendo que qualquer elemento de coesão existente, dizia respeito sobretudo à proteção e segurança.

Chama a atenção que muito embora houvesse essa descentralização, a raiz e origem dessa aparente relativização do conceito de soberania, é completamente distinta 
com o que vem a ocorrer com o fenômeno da globalização. Não havia a idéia de integração tal qual se verifica na globalização.

A idéia de soberania volta a ser reconsiderada com o advento da Idade Moderna e do Estado fortemente centralizado, com as Monarquias Absolutistas. 0 primeiro autor a formular de forma concreta um conceito de soberania foi Jean Bodin, que via na mesma o poder absoluto e perpétuo, a qual se enquadrava perfeitamente na figura representada pelo rei.

É claro que o conceito molda-se de acordo com a época, não sendo diferente 0 propósito de Jean Bodin, pois o mencionado autor queria uma formulação desvinculada à do direito divino, então vigente.

Rosseau desenvolve a teoria da soberania popular, com o povo sendo o titular do poder soberano, pois nesse momento o conceito de soberania era encarado de modo fragmentado, ou seja, era a soma das respectivas frações, inerentes aos indivíduos.

Durante a Revolução Francesa ocorre um deslocamento do conceito supracitado, isso porque é quando a burguesia, tendo atingido seus desígnios, resolve enquadrar e visualizar o conceito dentro das nações, como um corpo, o qual a exerce através de seus representantes devidamente escolhidos.

Em um segundo momento surge a teoria da soberania do Estado, o qual é ao mesmo tempo causa e justificativa do respectivo poder. É importante notar que tal teoria serviu de fundamentação ao totalitarismo, pois a vontade do Estado torna-se preponderante, pelo fato de possuir e ser a fonte da mesma, entendida aqui como sendo um poder de direito ou jurídico.

Outro momento marcante é a teoria realista, entendendo a soberania como atributo do Estado, porém, ressaltando a unidade de personalidade entre Estado e nação, podendo a nação, fazendo uso da soberania popular, retomar o poder originário, sempre que ocorrer uma dissociação entre a vontade do Estado e a de sua população.

Assim, a noção contemporânea de soberania possui raiz nas teorias desenvolvidas na Idade Moderna, sendo hoje compreendida - e até mesmo internalizada no Brasil a nível constitucional - como sendo um poder uno, imprescritível, inalienável e ilimitado, inerente a todos os estados-nação de que é detentor a coletividade organizada enquanto nação. 
0 poder constituinte, ainda que originário, deriva dessa idéia de soberania, sendo um resultado ou efeito da soberania popular, fazendo papel de substrato. A soberania, dentro de uma concepção moderna, se configura na participação das nações na ordem jurídica internacional, pois a partir desse momento ocorre a manifestação da mesma.

Assim que Paulo Napoleão Nogueira da Silva (2000, p. 23) entende que o conceito de soberania hoje se cede parcialmente para se integrar à ordem mundial. Em sentido semelhante, Ives Gandra da Silva Martins (1998, p. 13) entende que se está a viver a era do Estado Plurinacional, havendo uma espécie de Federação de países para a formação de um consenso universal.

O conceito assim passou a ganhar certa relatividade, sendo que é aceito, na conjuntura atual, a intervenção de certas nações em outras com o intuito de preservar os direitos que são imanentes a pessoa humana.

Uma ordem internacional, comprometida com a dignidade do ser humano, não pode conferir um status absoluto aos Estados, com os mesmos tendo plena autonomia sobre a população.

E justamente isso é o que vem sendo observado precisamente no momento atual, em que o mundo assiste às revoluções ocorridas no Oriente Islâmico, onde da iniciativa popular parte o anseio para uma nova ordem, sendo tais revoluções justamente a materialização de que o Estado não tem uma absoluta integridade que lhe dê o direito absoluto de determinar os seus povos, sem a observância de critérios mínimos universalmente válidos. Contudo, de se ressaltar, que tais revoluções são civis e internas, sem iniciativa de organismos internacionais.

Verifica-se, assim, que o conceito moderno em um primeiro momento nasce para fundamentar a intervenção do Estado moderno (a idéia do Estado Soberano do Monarquismo Absolutista), e hoje adquire novos matizes frente às novas concepções vigentes.

Um outro ponto que corrobora com esse novo paradigma diz respeito ao processo de integração das nações, pois uma legalidade supraestatal vem se formando no desenrolar do processo de globalização, sobretudo as Organizações Não Governamentais, internas ou externas, bem como as iniciativas privadas que avançam além de suas fronteiras dos países em que foram constituídas. 
Enfim, novas concepções em torno do conceito de soberania surgem no desenrolar do século XX e avançam no século XXI, século aquele marcado pela predominância de corporações comprometidas com resultados eficientes no que concerne aos lucros, não respeitando, dessa forma, qualquer relação ou concepção acerca da soberania das nações, atacadas pela audácia do capital especulativo.

Paralelamente a isso, o Direito Internacional Público ergue todo um aparato de princípios e conceitos a reger as relações recíprocas entre os Estados, sendo que o respeito aos direitos humanos torna-se imperativo, acima de qualquer ordem interna.

\section{O fenômeno da globalização e seus reflexos na soberania}

Costuma-se considerar a globalização como algo típico da contemporaneidade, sobretudo a partir da segunda metade do século XX. Entretanto, há dois paradigmas que podem ser apontados: por um lado, a noção de que na Idade Média a idéia de nação e soberania era relativizadada; e por outro lado, a noção de que o expansionismo mercantilista nada mais foi senão um primeiro reflexo da idéia da globalização.

$\mathrm{Na}$ Antiguidade evidentemente havia a necessidade de troca de mercadorias entre as nações. Nem sempre as relações eram pacíficas, mas Grécia e Roma desenvolvera o chamado "Direito das Gentes".

0 expansionismo, idéia inerente a todas as civilizações da Antiguidade, por outro lado demonstra a idéia de que se deve ampliar as fronteiras e conquistar novos espaços, muito embora, justamente ligado à idéia oposta da globalização: o território é da civilização dominante, não devendo sofrer qualquer intervenção de outra civilização.

Após o grande expansionismo Romano, a dissolução do Império Romano é justamente paradigma para marcar o fim dessa primeira noção de Estado e suas relações territoriais. Chega-se então à Idade Média, na qual os juristas teólogos começam a sistematizar e ressaltar a importância de uma teoria de doutrina internacional, facilitada até mesmo pelo modo de organização do Estado M edieval, mas ainda desprovido da noção de globalização tal qual se tem hoje em dia, conforme já ressaltado anteriormente.

Com o Congresso de Westphalia temos um novo desenvolvimento do Direito Internacional com o surgimento das bases do Estado Moderno. E isso se reflete através do 
início dos ciclos das navegações, que são a primeira manifestação de elementos que caracterizam a globalização.

O expansionismo mercantilista buscava conquistar novos mercados e associou-se a isso a idéia de expansão territorial. Seja com o intuito de se levar a cultura cristã ocidental a povos que desconheciam a noção de civilização ocidental, seja para a expansão territorial como forma de servir para a exploração de cultivos agrícolas.

Por outro lado, Jo (2004, p. 55) esclarece que o expansionismo europeu deparou-se com a diversidade de Direito Internacional em relação aos demais países em que os europeus realizavam suas trocas comerciais (a exemplo da Índia). Os europeus foram assim obrigados a admitir que o seu direito não era ilimitado, mas deveria se coordenar com a existência de outro Direito, com outros costumes. Esse expansionismo, que diferente do expansionismo da Antiguidade, que estava ligado à idéia de território soberano, sobretudo soberania política e de poder, aqui se liga à idéia de um expansionismo comercial, para girar a riqueza e sustentar o Estado Moderno.

O próximo paradigma marcante é o Congresso de Viena, quando surgem as primeiras normas internacionais significativas. Contudo, carecia ainda de institucionalização.

0 mundo Pós-Guerra conhece então a noção da Globalização, sendo visto como este fenômeno que visa a integrar o mundo constituindo uma unidade formada com 0 objetivo de desenvolvimento econômico, humano e social, num primeiro momento focado para a reconstrução da Europa decaída pela Guerra.

Foi neste contexto todo, já no século XX, que surgem as grandes Organizações Internacionais, a maior freqüência na celebração de Tratados de nível mundial, surgimento das Organizações Não Governamentais internas e da importância do Direito Internacional Público para efetivar a paz, conciliando com as novas descobertas do mundo moderno.

É válida a idéia de que não se define globalização, assim como não se define modernismo. A globalização não é propriamente um movimento, não é algo concreto, tocável. É simplesmente um fenômeno que age a nível mundial, e cuja idéia básica é a de supressão das diferenças culturais com base numa ideologia "comum" de nível global para uma integração mundial ordenada à idéia de desenvolvimento em todos os campos. 
Nisso tudo, tem-se o surgimento da internet e a sua dissociação, que era talvez a ferramenta que faltasse para que a cultura mundial e a integração mundial se integrasse numa velocidade muito maior que através das mídias tradicionais.

Com a internet, qualquer sujeito localizado em qualquer lugar do mundo pode ter acesso universal à informação, pode adquirir produtos on-line ou apenas efetuar a compra on-line de produtos localizados na outra parte do globo. Não somente empresas realizam contratos internacionais, mas qualquer cidadão ao alcance de apenas um clique.

A globalização se esbarra na questão das minorias e da proteção das culturas primitivas. Como conciliar a Globalização com as culturas de minorias? Este é o grande desafio que se apresenta à globalização.

Os autores em geral entendem a globalização sob uma ótica tridimensional, caracterizada pela ineficácia do Estado perante as mudanças que ocorrem em cenário global, manifestadas sobretudo pela diminuição das fronteiras espaciais e temporais e manifestadas através do desenvolvimento, democracia e direitos humanos.

Os estudiosos da área de Administração e Marketing apontam os denominados agentes indutores de globalização, tais como a necessidade comum dos consumidores, os consumidores globais, a concorrência internacional, a necessidade de expansão dos negócios, além de outros elementos (YIP, 1992, p. 33-34).

Há que se atentar para não confundir o fenômeno da globalização com relação a qualquer coisa que diga respeito a aspectos internacionais. (YIP, 1992, p. 14).

\section{A idéia de desenvolvimento ligada à globalização}

A noção de desenvolvimento se revela em três faces: o desenvolvimento econômico, humano e social para ao fim integrar-se e ter-se o conceito de desenvolvimento completo.

Fala-se no Direito Internacional no chamado direito internacional ao desenvolvimento, de que seriam titulares os países em desenvolvimento. Segundo Villar (apud MELLO, 2004, p. 683, v.2), a partir de 1945, 80\% das regras de Direito Internacional são de natureza econômica. É o denominado Direito Internacional Econômico. Maurice Flory, citado por Celso Albuquerque de Mello (2004, p. 683, v.2) defende que o Direito 
Internacional está a serviço de um projeto de constituição de uma nova ordem econômica internacional.

Falar de desenvolvimento econômico é falar também de crescimento econômico. Muito embora a priori tais conceitos pareçam ser sinônimos, na prática eles se revelam conceitos totalmente diferenciados. 0 crescimento econômico diz respeito, basicamente, ao crescimento do Produto Nacional.

0 produto nacional é o "Valor de todos os bens e serviços finais produzidos em determinado período de tempo" (VASCONCELLOS; GARCIA, 2004, p. 233). Difere-se do PIB, que considera apenas os fatores internos, ou seja, dentro do território nacional. Isso faz com que haja diferença entre os valores reais do PIB e do PNB. No caso do Brasil e demais países subdesenvolvidos, o PIB revela-se maior que o PNB.

Uma vez que há crescimento do produto nacional, há, sucintamente, crescimento econômico. É claro que para este crescimento se revelar de fato, é necessário que ele seja superior ao crescimento populacional. Essa é considerada a condição-base de crescimento econômico e também de desenvolvimento.

Posto o que é o crescimento econômico, pode-se agora falar no conceito de desenvolvimento econômico. 0 termo desenvolvimento econômico é muito mais amplo do que 0 de crescimento, e requer alguns requisitos básicos para que se possa caracterizá-lo. 0 desenvolvimento econômico consiste na expansão contínua da renda per capita de uma economia, com melhorias sistemáticas do bem-estar da população. (SOUZA, 1997, p. 333).

Assim, o desenvolvimento econômico abrange um lado qualitativo, e não apenas meramente quantitativo. Para haver o desenvolvimento, é necessário que o crescimento econômico se reflita com efeitos práticos na população, mediante melhor distribuição de renda (quer dizer, renda per capita), expectativa de vida, taxa de analfabetismo, mortalidade infantil, dentre outros.

O Direito Internacional vê o homem como objeto. É a chamada teoria do homemobjeto. Sendo o homem objeto do Direito Internacional, as suas relações são de interesse do Direito Internacional Público. De modo que todos os cidadãos que habitam em seus países têm direito ao desenvolvimento. Mas o que vemos na prática é que o desenvolvimento econômico não basta. 
Essa visão tipicamente mercantil-econômica passa a encarar uma nova realidade: 0 chamado Desenvolvimento Social. Pode-se tomar como exemplo os países do Oriente Médio. Não se pode dizer que são países subdesenvolvidos economicamente, contudo isso não se reflete na realidade social. E não se reflete porque há questionável desenvolvimento social face ao desenvolvimento econômico.

O desenvolvimento social leva em conta a superação e erradicação da miséria e da fome, a progressiva melhora da situação de vida dos pobres, a melhor distribuição de renda e capital entre a população, o pleno acesso à saúde e educação, que provoque gradualmente, melhoria na expectativa de vida, redução da mortalidade infantil e remuneração digna do trabalho.

Embora de difícil auferição, a Economia criou dois índices que buscam materializar o desenvolvimento: Índices de Desenvolvimento Humano (IDH) e também o Índice de Desenvolvimento Social (IDS).

Sucintamente, a metodologia de criação dos índices gerais, IDH e IDS são similares, pois a construção do índice geral deriva das médias de índices parciais. Eles variam no intervalo entre zero e um. Quanto mais próximo de um, indica maior proximidade em relação à alta aferição de desenvolvimento e quanto mais próximo de zero, maior afastamento em relação aos padrões mais altos aferidos.

o Desenvolvimento Social está intimamente ligado à noção de Desenvolvimento Humano. Sendo a Dignidade da Pessoa Humana um princípio do Direito Internacional e tendo em vista a noção de Direito ao Desenvolvimento e da Proteção do Homem Objeto, surge o binômio Desenvolvimento Social e Humano.

A noção de Desenvolvimento Social e Humano envolve Direito à saneamento, saúde física e psíquica, proteção dos marginalizados, condições mínimas de vida, dentre outros. Vê-se, pois, que possui campos distintos do Desenvolvimento Econômico tão-somente.

A noção do Desenvolvimento Humano leva ainda em consideração o respeito aos direitos humanos, sobretudo a dignidade da pessoa humana, a democracia e o direito à transparência política e de gestão do interesse público e a participação da sociedade na tomada de decisões que Ihe afetam. Em síntese, o Direito Internacional Humano visa à proteger os indivíduos, seja qual for a sua nacionalidade, sendo uma construção tipicamente pós-guerra (M AZZUOLI, 2008, p. 745). 
Esse é um dos grandes objetivos das revoluções democráticas que sobretudo o Oriente Islâmico vem assistindo. A alternância de poder, a participação popular na construção da vontade do Estado. Superar, enfim, na prática a política do pão e circo. M uito mais que condição econômica e social.

\section{As organizações internacionais frente ao papel do desenvolvimento e globalização}

Celso D. de Albuquerque de M ello (2004, p. 601) concorda com a definição dada por Angelo Piero Sereni sobre organizações internacionais, citando-a: "[...] organização internacional é uma associação voluntária de sujeitos de direito internacional, constituída por ato internacional e disciplinada nas relações entre as partes por normas de direito internacional."

As Organizações Internacionais podem ter diferentes objetivos. Podem ser de alcance universal e de alcance regional, sob o ponto de vista de amplitude. Sob o ponto de vista de finalidade, podem ser de vocação política ou de vocação técnica específica.

As de vocação técnica específica são aqueles organismos regulamentadores de questões técnicas, tal como Organização da Aviação Civil. Já as de vocação política são aqueles que se objetivam ao desenvolvimento dos Estados, tal como a ONU.

Dentre os objetivos da ONU, que são encontrados na Carta da ONU, vislumbra-se em seu artigo 10 o objetivo de manter a paz e segurança internacional, desenvolver as relações amistosas entre os Estados, merecendo destaque, ainda, a cooperação internacional para resolver problemas internacionais de natureza econômica, social, cultural e humanista².

As Organizações Internacionais de caráter político assumem um papel significativo dentro do papel da Globalização e do Desenvolvimento das nações. 0 seu papel é conciliar os diferentes interesses que surgem nas relações inter-estatais e criar mecanismos aptos para que cada Estado adote medidas que visem ao pleno desenvolvimento.

Justamente as organizações de vocação política materializam na prática esse ideário da universalização de direitos mínimos, como os direitos humanos e ao desenvolvimento.

\footnotetext{
${ }^{2}$ Artigo 1. Os propósitos das Nações unidas são: [...] 3. Conseguir uma cooperação internacional para resolver os problemas internacionais de caráter econômico, social, cultural ou humanitário, e para promover e estimular o respeito aos direitos humanos e às liberdades fundamentais para todos, sem distinção de raça, sexo, língua ou religião. Carta da ONU, disponível em: http://www.onu-brasil.org.br/documentos_carta.php>, Acesso em: 15 fev 2011.
} 


\section{Novos desafios do Direito Internacional ante esse quadro}

Não é difícil imaginar que o Direito Internacional vai adquirir uma importância cada maior com este fenômeno cada vez mais crescente da integração mundial. 0 simples fato de que hoje em dia é acessível a qualquer consumidor pessoa física efetuar compras em qualquer parte do mundo sem sair de sua casa já bem demonstra a que ponto chegou esta integração.

Que lei protegerá o consumidor que adquire em qualquer parte do globo um produto vendido por uma empresa num website? Ou que lei protege o usuário de um software licenciado e pago, cuja sede do autor esteja em qualquer parte do mundo? A regra tradicional da onde a obrigação se constitui aplica-se a esses contratos celebrados pela internet? Onde se constitui a obrigação, no computador do usuário que baixa um software ou no site em que se localiza o software?

Todas essas são apenas alguns dos problemas que deverão ser enfrentados. Não se tem dúvida num primeiro momento de que hoje o Direito Internacional oferece suporte para as tradicionais formas de relacionamento entre os Estados uns com os outros ou entre empresas de diferentes nacionalidades.

Porém a expansão provocada pela internet e a integração vai gerar conflitos inevitáveis que precisarão ser resolvidos. Sem dúvida haverá necessidade de se celebrar tratados para compatibilizar e criar mecanismos eficazes para a regulação dessas pequenas relações comerciais ou não celebradas pela internet entre membros de diferentes nacionalidades.

Além do desafio provocado pela internet, existe também a possibilidade do choque cultural que se pode provocar entre sujeitos que não fazem parte deste processo de integração. 0 maior exemplo são as barreiras de pleno acesso à internet em países como a China.

Nas revoluções democráticas que vêm ocorrendo no Oriente, a ferramenta que desencadeou as revoluções que buscam destituir os governos vitalícios foi justamente a internet, pelo acesso que tinham as novas gerações a um mundo distante de sua realidade.

o capital intelectual com o mundo integrado é outro fator que tende a fazer com que um sujeito leve o seu conhecimento e métodos para um outro país que não disponha 
daquela tecnologia e tem a necessidade de importar essa informação. É a fuga do capital intelectual.

Há que se ressaltar também dois fatores que limitam a atuação estatal: por um lado, a subordinação a normas de Direito Internacional, que impedem um país de adotar políticas que fortaleçam a sua própria nação, mas que estejam em desacordo com alguma norma internacional (ex: o subsídio de determinados produtos comerciais); por outro lado, há a questão do super acesso à informação, que inevitavelmente propicia à sociedade um controle da política estatal de maneira praticamente instantânea, podendo usar as manifestações populares para demonstrar o seu descontento com as políticas adotadas pelo Estado.

Assim, a atuação do Estado sofre certa limitação face à observância que tem, de um lado da sociedade, e de outro, das entidades não governamentais (Organizações Internacionais). Esse processo, desencadeado pela globalização tem levado à desconcentração, descentralização e fragmentação do poder, no entender de José Eduardo Faria (1999, p. 7).

Por fim, merece ressaltar que sempre se pôs como grande adversário da globalização e deste fenômeno da mundialização, 0 direito das minorias. 0 direito à preservação cultural, que faz parte inclusive dos objetivos da ONU, conforme já visto.

Esse processo desencadeado no Oriente talvez tenha despertado um dos pontos mais delicados: até que ponto as minorias devem ser protegidas dos efeitos da globalização? Até que ponto os povos de cultura distinta querem manter essa distinção? Até que ponto é política governamental ou até que ponto é opção de um dado grupo, povo ou nação? Podese fugir do processo de globalização?

\section{Conclusão}

Não se tem dúvida de que cada vez mais o mundo parte uma integração a nível mundial. De momento esta integração é materializada através da globalização, sobretudo no Ocidente. Tal processo é compreensível sob uma análise histórica da civilização ocidental.

O processo para se chegar ao aparente consenso mínimo que se tem hoje em dia quanto a valores como democracia, participação popular, alternância de poder, direitos 
mínimos, direitos humanos, passou pelo Direito Internacional, que assistiu a todo este processo até culminar no que temos hoje.

Só é possível falar em globalização efetivamente se se levar em conta valores como a soberania e o desenvolvimento, entendido em todos os seus aspectos. Com essa integração que existe hoje no mundo, tem-se assistido na atualidade à eclosão de revoluções no Oriente, sobretudo Oriente Islâmico, cujo objetivo é integrar-se nesse papel.

Talvez o grande obstáculo seja o elemento cultural. Pode-se questionar se tais nações do Oriente estão preparadas para ingressar nessa ordem mundial, face à sua cultura típica e um tanto distante do padrão ocidental. Ao mesmo tempo, conforme já visto anteriormente, tem-se que neste processo a iniciativa foi popular, o que dá um indicativo de uma possibilidade de integração do Oriente à cultura Ocidental, diminuindo talvez parte das barreiras culturais mais significativas.

0 grande questionamento que se deve extrair é se o Direito Internacional está preparado para esta nova realidade. E um desafio é se haveria necessidade de se rever o aparato normativo que existe no Direito Internacional hoje. 0 Direito Internacional necessita estar antenado à essa realidade.

\section{Bibliografia}

ARIOSI, Mariângela F. As relações entre o Direito Internacional e o Direito Interno. Jus Navigandi, Teresina, a. 9, n. 498, 17 nov. 2004. Disponível em: বhttp://www1.jus.com.br/ doutrina/texto.asp?id=5940>. Acesso em: 13 nov. 2008.

BITTAR FILHO, Carlos Alberto. Evolução histórica do direito internacional. Revista de Informação Legislativa, Brasília, ano 29, n. 115, p. 381-393, 1992.

FARIA, José Eduardo. O Direito na Economia Globalizada. São Paulo: Malheiros, 1999.

J0, Hee M oon. Introdução ao Direito Internacional. 2. ed. São Paulo: LTr, 2004.

LITRENTO, Oliveiros. Curso de Direito Internacional Público. 5. ed. Rio de Janeiro: Forense, 2003.

M ARTINS, Ives Gandra da Silva (Coord.). O Estado do Futuro. São Paulo: Pioneira, 1998.

M ATTOS, José Dalmo Fairbanks Belfort de. Manual de Direito Internacional Público. São Paulo: Saraiva Educ., 1979. 
M AZZUOLI, Valério de Oliveira. Curso de Direito Internacional Público. 3. ed. rev. atual. e ampl. São Paulo: RT, 2008.

MELLO, Celso D. de Albuquerque. Curso de Direito Internacional Público. 15. ed. rev. e ampl. Rio de Janeiro: Renovar, 2004, v.1.

MELLO, Celso D. de Albuquerque. Curso de Direito Internacional Público. 15. ed. rev. e ampl. Rio de Janeiro: Renovar, 2004, v.2.

M IALHE, Jorge Luís. Desafios no Ensino do Direito Internacional Público e do Direito da Integração em Tempos de Globalização. Revista Impulso, Piracicaba, v. 14, n. 33, p. 85-112, 2003.

NUNES JUNIOR, Venilto Paulo. O Conceito de Soberania no Século XXI. Revista de Direito Constitucional e Internacional, São Paulo, v. 42, p. 145-166, 2003.

ONU BRASIL. Carta da ONU. Disponível: «ttp://www.onu-brasil.org.br/documentos_ carta.php>. Acesso em: 15 fev. 2011

RANGEL, Vicente Marotta. Direito \& Relações Internacionais. 8 ed. rev. atual. e ampl. São Paulo: RT, 2005.

REZECK, José Francisco. Direito Internacional Público: curso elementar. 9. ed. São Paulo: Saraiva, 2002.

ROSSETTI, José Paschoal. Introdução à Economia. 19. ed. São Paulo: Atlas, 2002.

SILVA, Paulo Napoleão Nogueira da. Direito Constitucional no M ercosul. Rio de Janeiro: Forense, 2000.

SOUZA, Nali de Jesus de (Coord.). Introdução à Economia. 2. ed. São Paulo: Atlas, 1997.

VASCONCELLOS, Marco Antonio S.; GARCIA, M anuel E. Fundamentos de Economia. 2. ed. São Paulo: Saraiva, 2004.

YIP, George S; ANTONIONILI, Rosana. Globalização: Como enfrentar os desafios da competitividade internacional. São Paulo: Senac, 1992.

Artigo recebido em: 20 de março de 2011. 